\title{
Benlik Yapısı, Romantik İlişki Biçimleri ve Cinsiyet Arasındaki İlişki
}

\author{
Rıdvan ÜNEY*, Elif GÜNERI YÖYEN**
}

\begin{abstract}
Öz
Benlik yapısı, romantik ilișki biçimleri ve cinsiyet arasındaki ilişkiyi incelemek için yapılan bu araştırmanın verileri 2018-2019 eğitim öğretim yılının güz yarıyılında İstanbul Gelişim Üniversitesi, İktisadi İdari ve Sosyal Bilimler Fakültesi'nde öğrenim görmekte olan 400 üniversite öğrencisinden elde edilmiştir. Araştırma verileri, İlişkisel-BireyciToplulukçu Benlik Ölçeği (RIC) ile Așka İlișkin Tutumlar Ölçeği (LAS) kullanılarak toplanmıș, verilerin analizinde; ölçek güvenilirlikleri için Cronbach Alfa değerleri, Benlik Yapısı ile Romantik İlișki Biçimleri arasındaki ilișkinin tespiti için Pearson Korelasyon Analizi, cinsiyete göre benlik yapısı ile romantik ilișki biçimleri arasında anlamlı farklılık olup olmadığının tespiti için bağımsız örneklem $t$ testi uygulanmıștır. Analiz sonucunda bireycilik benlik yapısı ile tutkulu, arkadaşça ve mantıklı aşk biçimi arasında; ilișkisellik benlik yapısı ile tutkulu, mantıklı, sahiplenici ve özgeci aşk biçimi arasında; toplulukçuluk benlik yapısı ile arkadaşça, mantıklı, sahiplenici ve özgeci aşk biçimi arasında pozitif yönlü anlamlı bir ilişki olduğu; erkeklerde oyun gibi ve özgeci aşk biçiminin kadınlara göre daha yüksek düzeyde, kadınlarda mantıklı aşk biçiminin erkeklere göre daha yüksek düzeyde yaşandığı ve son olarak kadınların erkeklere göre daha yüksek düzeyde bir bireycilik benlik yapısına sahip oldukları tespit edilmiștir.
\end{abstract}

Anahtar Kelimeler: Benlik Yapısı, Benlik, Așk, Romantik İlișki, Cinsiyet, İstanbul Gelişim Üniversitesi, İktisadi İdari ve Sosyal Bilimler Fakültesi

\section{The Relationship Between Self Structure, Romantic Relationships and Gender}

\section{Abstract}

The data of this study, which was conducted to examine the relationship between self structure, romantic relationships and gender, were obtained from 400 university students who were studying at Istanbul Gelisim University, Faculty of Economics, Administrative and Social Sciences in 2018-2019 academic year. The research data were collected by using Relational-Individualist-Communityist Self-Scale (RIC) and Attitudes Towards Love Scale (LAS). As a result of the analysis, individualism is between the self

\section{Özgün Araştırma Makalesi (Original Research Article) \\ Geliş/Received: 28.03 .2019}

Kabul/Accepted: 19.02 .2020

DOI: https://dx.doi.org/10.17336/igusbd.542947

* Dr. Öğr. Üyesi, Nişantaşı Üniversitesi, İktisadi, İdari ve Sosyal Bilimler Fakültesi, Psikoloji Bölümü, İstanbul, Türkiye, E-posta: ridvanuney@gmail.com; ridvan.uney@nisantasi.edu.tr

\section{ORCID ID https://orcid.org/0000-0003-1933-3334}

${ }^{* *}$ Dr. Öğr. Üyesi, Nişantaşı Üniversitesi, İktisadi, İdari ve Sosyal Bilimler Fakültesi, Psikoloji Bölümü; Mavi Martı Psikolojik Danışma Merkezi, İstanbul, Türkiye, E-posta: elifguneri@gmail.com ; elif@mavimarti.net ORCID ID https://orcid.org/0000-0002-0539-9263 
structure and passionate, friendly and sensible way of love; the relationship between self structure, passionate, logical, possessive and altruistic forms of love; there is a positive meaningful relationship between self concept and selfishness, friendship, logical, possessive and altruistic forms of love; it was found that men like altruism and altruistic forms of love were higher than women and women had a higher level of sense of love than men, and women had a higher level of individualism than men.

Keywords: Self Structure, Self, Love, Romantic Relationship, Gender, Istanbul Gelisim University, Faculty of Economics, Administrative and Social Sciences

\section{Giriş}

İnsan tek başına yașamayan, ötekiyle olan ilișki ile tanımlanan ve yakın ilişki arayıșında olan bir canlıdır. Romantik ilişki ya da aşk, bazen ilişkinin tanımı, bazen bir ilişkinin özelliklerinden biri ya da insanın ötekine hissettiği duyguyu belirtir. Aşkta her zaman ötekine ihtiyaç vardır (Rotenberg, 2001; Durmaz \& Ercan, 2019).

Așkın; yakınlık, bağlanma, içe yatırım, güven, saygı, sevgi gibi bileşenleri vardır. Bu haliyle aşk, Pozitif Psikolojinin etkisiyle dünyada ve Türkiye'de alan yazında daha fazla yer tutmaya başlamıştır. Aşkın tanımında kültürün ve bireyselliğin önemi büyüktür. Bununla birlikte araştırma yapanlar aşkı farklı șekillerde ve farklı yönlerden değerlendirmişlerdir. Araştırmacılar aşkı; bireysel, toplumsal, evrimsel veya nöropsikolojik yönden değerlendirmişlerdir (Sternberg, 1999). Araștırma motivasyonumuz; son zamanların bu ilgi çeken konuda; cinsiyet ve kültürün etkisiyle oluşan benlik biçimlerinin ilişkisini ortaya koymak suretiyle, alana katkı sağlamaya çalıșmaktır.

\section{Benlik Yapıları}

Psikoloji alan yazınında self; zaman zaman kendilik, zaman zaman benlik olarak adlandırılmıştır. Bunun en önemli nedeni; Kohut'un kendilik (self) psikolojisi kuramını olgunlaştırırken kat ettiği yolla ilişkilidir.

Kohut (Kohut, 1971); teorinin ana eksenini oluşturan kendiliği(self), ilkin benlikte yer alan bir kendilik temsilcisi (self representation)-(kişinin kendini algilayış biçimi ve kendisiyle ilgili bilinçte yansıyan görüntü bütünü)- diye tanımlamışken, sonrasında bir üst örgütlenme, "kişiliğin çekirdeği, algıların ve girişimlerin merkezi" şeklinde tarif etmiştir (Kohut, 1977). Teorinin diğer temel tanımı olan "kendilik nesnesi"ni ise çocuk tarafından kendiliğin işlevsel kısmı olarak algılanan, "biraz ben / biraz öteki, hem ben / hem öteki" olan nesne olarak tariflemiștir (Erten, 2002).

Kohut'un kendilik psikolojisi kuramında kendilik, bebeğin ve daha sonra çocuğun idealize edilmiş ve aynalayan kendilik nesneleriyle yaşadığı tecrübeleri özümsemesi sonucunda gelişir.

Kendiliğin gelişiminde doğal olarak ötekine ihtiyaç vardır. Metinin bundan sonraki bölümlerinde karmaşa olmaması için; aynı anlamda olmak üzere, kendilik yerine benlik terimi kullanılacaktır.

Benlik kavramını açıklamak güçlük içermektedir. Benlik; genel olarak, bilişsel ve duygusal süreçlerin örgütlenmesi ve davranışların düzenlenmesinde etkide bulunan bir "yapı" (Singelis, 1994), bireyin çevresi ve sosyal hayatıyla etkileşimi sonucunda belirginleșen dinamik bir "süreç" (Banaji \& Prentice, 1994) olarak değerlendirilebilir. "Benlik", psikolojik yapılanmamızı anlamamızda bize yardımcı olacak soyut, önemli bir kavramdır. Hatta çoğu zaman sadece farklı benliklerle etkileşimde olduğumuz zamanlarda, aradaki farklılıkları görebiliriz. Kültürel özellikler, farklı benlik kurgularının 
şekillenmesinde rol oynar ve benlik kurgusu aracılığı ile de; biliş, duygu ve dürtüleri etkilemektedir.

Benlik yapısı (self construal); benliğin ötekiyle ilişkisine ait düşünce, duygu ve davranışlarıyla birlikte ötekinden farklılaşması olarak söylenebilir. (Singelis \& Sharkey 1995). Bireyin kültürel yönelimi, yani kültürden etkilenme, benlik yapısının oluşumunu etkilemektedir (Singelis, 1994).

Kültürden etkilenen benlik yapıları doğal olarak farklı ülkelerde de farklı şekillerde karşımıza çıkacaktır. Markus ve Kitayama (1991) Avrupa, Amerika ve Asya kültürlerinde oluşan farklı benlik biçimlerini inceleyerek, "Benlik Yapıları (Self Construals)" kuramını ve benliğin Amerika ve Japon kültüründeki anlam, içerik ve tanımlarını oluşturmuşlardır.

Bireycilik-toplulukçuluk eğilimleri, farklı kültürlerin doğasında bulunmaktadır. Dolayısıyla benlik yapıları da bu doğrultuda kültüre bağlı davranıș deseni olușturacaktır. Toplumdaki yaygın bireyci ya da toplulukçu değerler, o toplumda oluşan benlik yapılarını açılklayabilecektir (İmamoğlu, 1998; Kağıtçıbașı, 1996, 2001, 2002; Kitayama \& Cohen, 2007; Markus \& Kitayama, 1991; Triandis, 2001).

Bireyci ya da bağımsız benlik; ayrı olma ve özerklik, karşılıklı bağımlı ya da toplulukçu benlik ise kişiler arası ilişkiler ve gruba aidiyet yoluyla, başkaları ile paylaşılan değerler olarak tanımlanabilir.

Kağıtçıbaşı (2005) aynı bireyin hem bireyci hem de toplulukçu davranışlar sergileyebileceğini ortaya koymuş, kişilerarası mesafe ve bireyleşmeyi iki ayrı ve bununla birlikte ilișkili boyutlar olarak değerlendirmiștir. Bu iki durumun, her birinin iki ayrı ekseni vardır: Kişiler arası mesafe ekseninde ilişkisellik ve ayrıșma, bireyleșme ekseninde özerklik ve bağlılık yer almaktadır (Kağıtçıbaşı, 2005). Benliğin bağımsızlık-karşılıklı bağımlılık şeklinde değerlendirilmesi, aynı zamanda kişiler arası ilişki yönelimli ve grup yönelimli, karşılıklı bağımlılık arasında bir ayrım yapmadığı için de eleştirilmiş ve bunun yerini ikili yerine üçlü bir benlik ayrımı almıştır (Bresnahan vd., 2005; Hardie, Kashima \& Pridmore, 2005; Kashima \& Hardie, 2000; Kashima vd., 2005; Ulema dv., 2000).

Dolayısıyla bireyci ve toplulukçu boyutla birlikte; ilişkisel benlik, yeni bir boyuttur (Kashima \& Hardie, 2000). Bu modelde:

1. Bireycilik boyutu: Bireyi başkalarından farklı, kendine özgü, yegâne olma özellikleriyle yansitan boyuttur.

2. İlişkisellik boyutu: Bireyin yakın çevresindeki bireylerle ilişkisini ve onlar gibi olma durumunu içerir.

3. Toplulukçuluk boyutu: Birey ve topluluk arasındaki simgesel değerleri yansitan boyuttur. (Ercan, 2011)

Hofstede'nin (1980) kültürel değerlerle örgütsel değişkenleri incelediği geniş araştırmasında; Kuzey Amerika odaklı örgütsel modelin diğer kültürlerde olmamasını sorgulanmaya başlandı. Kültürün benlik üzerine, bireysellik-toplulukçuluk bağlamında etkisinin araştırılması, kültürel değerlerin etkisini bir kez daha ortaya koymuştur. Ne var ki bu araștırmada aynı ülkedeki kültürün tekliği kabul edilmiștir. Bu araștırmada benlik yapısı örgütsel düzeyde aile ile sınırlandırılmış olup, kamusal alan ve yasal alanda değişkenliği dışlanmıștır. Kamusal alan ve yasal alanda çeşitli farklılıklar olabileceği kabul edilmiştir. Türkiyeli ve İsveçli kişilerin; ilişkisel ve özerk benlik yapılarını araştıran bir çalışmada, yașam şekilleri ve tutumlarına da bakılmış, Türkiyelilerde ilișkisel benliğin gelişimini; sosyal ve kültürel çevre, aile, yakınlar ve komşular tarafından desteklenmekte olduğu ilişki ve yakın bağların önemli olduğu ortaya konmuştur (İmamoğlu, 1998; Kağıtçıbaşı, 2010; Kağıtçıbașı, 2012).

Türkiyeli ve İsveçli kişilerin; ilişkisel ve özerk benlik yapılarını araştıran bir çalışmada, yaşam şekilleri ve tutumlarına da bakılmış, Türkiyelilerde ilişkisel benliğin gelişimini; sosyal ve kültürel çevre, aile, yakınlar ve komşular tarafından desteklenmekte 
olduğu ve ilişki ve yakın bağların önemli olduğu ortaya konmuştur (İmamoğlu, 1998; Kağıtçıbaşı, 2010; Kağıtçıbaşı, 2012).

Karakitapoğlu-Aygün'ün (Karakitapoğlu-Aygün 2004) Türk üniversite öğrencileri arasında yaptığı benlik, kimlik ve duygusal iyilik konulu araştırmasında benlik ve kimliğin en iyi tanımlayıcılarının, benliğin bağımsız ve ilişkisel-karșılıklı bağımlı alanları ve kimlik bulgusu olduğunu gözlemlemişlerdir. Toplulukçu-karşılıklı bağımlılık alanı ise benliği tanımlamaktan oldukça uzaktır. Düşünülenin aksine kadın erkek karşılaştırılmasında kadınlar, kendilerini daha bireyci ve daha az geleneksel betimlemişlerdir.

Çuhadaroğlu ve Akfırat'ın 2017'deki çalışmasından özerk-ilişkisel benlik kurgusunun, kadınlarda daha yüksek olduğunu tespit etmişleridir.

Benlik üzerine yapılan geçmişteki araştırmalar, cinsiyetin benlik yapıları üzerinde etkili olabileceğine işaret etmektedir (Bresnahan, Chiu \& Levine, 2004; Carpenter \& Karakitapoğlu-Aygün, 2005; Karakitapoğlu-Aygün, 2004a; Kashima \& Hardie, 2000; Lalonde vd., 2004; Madson \& Trafimov, 2001; Üskül vd., 2004).

Kadınlarda erkeklere göre; bireycilik ve ilişkisellik anlamlı derecede yüksek, bununla birlikte toplulukçuluk açısından farklılık yoktur.

Karakitapoğlu-Aygün'ün (2004) kadınların bireycilik puanlarının erkeklerden anlamlı bir şekilde yüksek bulduğu çalışmasında, kadınların erkeklerle karşılaştırıldığında kendilerini daha az geleneksel ve daha çok kişisel kelimelerle tanımladığı yorumlanmıştır. Carpenter ve Karakitapoğlu-Aygün'ün araştırma sonucu (2005) kadınların kişisel kimliğe erkeklerden daha fazla önem verdiğini göstermektedir. Üskül ve arkadașlarının araștırması (2004) kadınların bağımsız benlik yapısı skorlarının, erkeklerden anlamlı olarak yüksek olduğunu ortaya koymuştur. Benzer şekilde İmamoğlu (1998, 2003) ve Karakitapoğlu-Aygün'ün (2004) çalışmalarında kadınların hem bireycilik hem ilişkisellik puanlarının, erkeklerin puanlarından anlamlı olarak yüksek olduğu saptanmıştır. Ercan (Ercan, 2013a) çalıșmasında kadınlarda bireycilik ve ilișkisellik skorlarını erkeklerden daha yüksek bulmuştur.

\section{Romantik İlişki Biçimleri}

Aşk; edebiyat, felsefe ve sanatın oldukça ilgisini çekmiş ve hatta sanatın birçok alanına yön vermiştir. Așkın tanımında geçici olması esası vardır ve aşk kültüre göre şekil alır, doğası ise sınırlıdır (Tufan \& Yaluğ, 2010).

Batı alan yazınında aşk, etimolojik olarak " özleme, arzulama, doyum ve cinsel içgüdü" olarak tanımlanmaktadır (Tufan \& Yaluğ, 2010). Aşk kavram olarak kişisel, kültürel, sosyolojik, evrimsel ya da sinir-bilimsel alanlarda tanımlanmaya çalışılmakta ve doğal olarak birçok kuramca açıklanmaya çalışılmaktadır. Așkla ilgili çeşitli psikolojik kuramlar ortaya atılmıştır. Bunlardan ilk olanı Zick Rubin'e ait olanıdır. Rubin aşkı; içinde bilişsel, davranışsal ve duygusal alanlar içeren ve bireysel farklılıklar barındıran bir kültürel kavram olarak değerlendirmektedir. (Rubin, 1970, 1988). Sevgiliye duyulan ilgi ile arkadașa duyulan ilgi birbirinden duygu, düşünce ve davranıș bakımından farklılıklar içerdiğini öne sürmüştür. Rubin aşkın üç temel bileșen barındırdığını; bunların, yakınlık (intimacy), gözetme (caring) ve bağlanma (attachment) olduğunu söylemektedir. Yakınlığı, diğerlerinden ayrı olarak onunla daha rahat konuşma ve özel konuları paylaşma olarak tanımlamıştır. Gözetmeyi; kişinin ilgi duyduğu kişinin mutlu olmasını çokça önemsemesi ve bağlanmayı da eşle duygusal bağ olușturma olarak tanımlamıștır (Rubin, 1970). Rubin'in kendi geliştirdiği "Hoşlanma ve Aşk Ölçeği", aşk konusunda gerçekleştirilmiş ilk bilimsel çalışma ölçeği olarak değerlendirilir (Sternberg \& Grajek, 1984).

Aşkın bilimsel çalışmalarda Alan Lee'nin "Aşkın Renkleri” (The Colours of Love) kuramı, oldukça ilgi görmüştür. Lee kuramında aşkı; doğadaki ana ve ara renklerden 
esinlenerek kategorize etmiştir. Buna göre üç ana rengin karşılığı olarak üç temel/birincil aşk biçimi vardır: Tutkulu aşk (eros), oyun gibi aşk (ludus) ve arkadaşça aşk; diğer aşk biçimleri ise tıpkı ana renklerin karışımından oluşan ara renkler gibi; temel aşk biçimlerini üst üste binmesiyle yani karışmasıyla oluşur. Lee'ye göre arkadaşça aşk ile oyun gibi aşk, mantıklı aşkı (pragma), tutkulu aşk ile oyun gibi aşk sahiplenici aşkı (mania) ve tutkulu aşk ile arkadaşça aşk özgeci aşkı (agape) oluşturur ki bunlara da ikincil aşk biçimleri denir. Tutkulu aşkta fiziksel beğeni ve çekim, cinsel yönden etkilenme mevcuttur. Tutkulu aşkta şablon şeklinde bir fiziksel özellik aranmayabilir, bu durumda sadece aşka risk alma davranışları ve buna rağmen duygusal kontrol ön plandadır, Oyun gibi aşkın özelliği bağlanmanın az olduğu, eğlenmenin ve beraber zaman geçirmenin yoğun olduğu aşk biçimidir. Oyun gibi aşk stratejilerle doludur ve güvenilmezdir. Arkadaşça aşk çiftin bir arada uzun vakit geçirmeleri sonucunda ortak yönler ve birbirlerini kollamanın önemli olduğu aşk biçimidir. Heyecan çok yoğun değilse de, aşırılıklar da ve iniş çıkışlar da görülmez. Cinsellik ön planda değildir fakat geleceği daha tahmin edilebilir bir aşk biçimidir. Sahiplenici aşık kıskanç ve güvensizdir. Sevgilisi yanındayken oldukça heyecan ve coşku dolu, yokluğunda aşırı mutsuz ve umutsuzdur. Partnerini kaybetmek istemez, ayrılıktan yoğun şekilde etkilenir. Mantıklı aşk tipinde ilişkinin geleceğine inanılır, devamlılıkla ilişkili kuşku yoktur. Bu tipte uyum önemlidir ve kişiler partnerinin geçmişini önemserler. Kendi çerçeveleri vardır, sevgileri bu çerçeve içinde yaşarlar.

Özgeci aşık kendini ilişkiye adamıştır, özveri, vericilik, sabır, kararlılıkla beraber yoğun duygular yaşanır. Sevgili olduğu gibi kabul edilir ve kıskanılmaz. Onun iyiliği ön plandadır. Așkın karșılık bulması önemli değildir (Lee, 1974; 1988).

Erkeklerin tutkulu, arkadaşça, oyun gibi ve özgeci aşk puanları, kadınların tutkulu, arkadaşça, oyun gibi ve özgeci aşk puanlarından; kadınların mantıklı aşk puanları, erkeklerin mantıklı aşk puanlarından daha yüksektir (Durmaz \& Ercan, 2019).

Yapılan çalışmalarda erkeklerin oyun gibi aşk puanlarının anlamlı yüksek bulunması, hem Türkiye hem de diğer ülkelerdeki yapılan çalıșmalarda örtüșmektedir (Büyükșahin \& Hovardaoğlu, 2004; Davies, 2001; Dion \& Dion, 1993; Ercan, 2013b; 2016; Fehr, Harasymchuk \& Sprecher, 2014; Hendrick \& Hendrick, 1986; 1995; Le, 2005; Neto, 1994; Neto ve ark., 2000; Sharma \& Khandelwal, 2014).

Kadınlarda romantik ilişki biçimlerinde mantıklı aşk birçok araştırmada gözlenmiștir. (Avinash vd., 2015; Dion \& Dion, 1988; 1993; Philbrick \& Stones, 1988; Rosenman, 1978; Rubin, Peplau \& Hill, 1981; Smith \& Klases, 2016).

Ercan'ın (Ercan, 2013a) çalışmasında, Türkiye'deki genç yetişkinlerde romantik ilişki biçimleriyle benlik yapılarını karşılaştırılmış; bireycilik benlik yapısıyla tutkulu aşk ve arkadaşça aşk pozitif yönde, özgeci aşk ile ise negatif yönde bir ilişki içerisinde olduğu saptanmıștır. Aynı çalışmada, ilişkisellik ve toplulukçu benlik yapılarının tutkulu aşk, arkadaşça aşk, sahiplenici aşk, mantıklı aşk, ve özgeci aşk arasında pozitif yönlü anlamlı bir iliş̧i görülmüştür.

\section{Araştırmanın Problemleri}

Benlik yapısı, romantik ilişki biçimleri ve cinsiyet arasındaki ilişkinin incelendiği bu araștırmanın problemleri şunlardır:

1. Romantik ilişki biçimleri ve benlik yapıları arasında bir ilişki var mıdır?

2. Cinsiyete göre romantik ilişki biçimleri arasında anlamlı bir farklılık var mıdır?

3. Cinsiyete Göre benlik yapısı düzeylerinde anlamlı bir farklılık var mıdır? 


\section{Yöntem}

Alan yazını bilgisinde örneklemin tutum, inanç ve görüşlerinin araştırıldığı çalışmalarda tarama yönteminin kullanılması bilgisi ıșığında bu çalışmada ilişkisel tarama yöntemi kullanılmıştır (Yöyen, 2017).

\section{Evren ve Örneklem}

Araştırmanın evrenini, 2018-2019 eğitim-öğretim yılı, güz yarıyılında İstanbul Gelişim Üniversitesi, İktisadi İdari ve Sosyal Bilimler Fakültesi'nde öğrenim gören 3857 öğrenci oluşturmaktadır. Araştırmanın örneklemini ise evren kapsamında gönüllülük esasına göre araştırmaya katılan 1., 2., 3. ve 4. sınıflarda öğrenim gören toplam 400 katılımcı olușturmaktadır. Araștırmaya katılan öğrencilerin 200'ü kız (\%50), 200'ü erkektir (\%50).

\section{Veri Toplama Aracı \\ İlişkisel Bireyci Toplulukçu Benlik Ölçeği (RIC).}

Kashima ve Hardie (2000) tarafindan bireyci, ilişkisel ve toplulukçu benlik yönlerini değerlendirmek için geliştirilmiş olan ölçeğin Türkçeye uyarlanma çalıșması Ercan (2011) tarafından yapılmış olup, iç güvenirlik analizinde çin Cronbach Alpha katsayısı alt boyutlar için .68 ile .86, test-tekrar test güvenirliği ise .79 olarak rapor edilmiştir. Ölçek, birbirini takip eden ve her biri üç benlik yönünü yansitan maddeler barındıran 10 sorudan (toplam 30 madde) oluşmaktadır. Ölçek yedili likert tipindedir. Her bir alt ölçekten alınacak puanlar 10 ile 70 arasında değişebilmektedir. Alt ölçek puanları bireyin durumsal bir dağılım karşısında her bir benlik yöneliminin genel derecesini ortaya koymaktadır (Ercan, 2011).

\section{Aşka İlişkin Tutumlar Ölçeği (LAS)}

Bireylerin aşk biçimlerini belirlemek amacıyla Lee'nin aşk biçimleri sınıflandırması temel alınarak Hendrick, Hendrick ve Dicke (Hendrick, Hendrick \& Dicke, 1998) tarafından geliştirmiş; Büyükşahin ve Hovardaoğlu (Büyükșahin \& Hovardaoğlu, 2004) tarafından Türkçeye uyarlanmış olan ölçeğin, uyarlama çalışması sonucunda iç tutarlılığı için Cronbach Alfa katsayısı .70, iki yarım güvenilirliği .70 olarak hesaplanmıştır. LAS ölçeği tutkulu aşk, özgeci aşk, sahiplenici aşk, oyun gibi aşk, arkadaşça aşk, mantıklı aşk olmak üzere altı farklı aşk biçimini ölçmektedir. LAS her bir aşk biçimini ölçmeye yönelik dört madde olmak üzere toplam 24 maddeden oluşmaktadır (Açıel, 2013).

\section{Verilerin Analizi}

İlişkisel tarama modelindeki bu araştırmada veri setinin güvenilirlik çalışması için Cronbach Alfa katsayısı hesaplanmıștır. Buna göre kullanılan LAS ölçeğinin alt boyutlarndan Tutkulu Așk 0.880, Oyun Gibi Așk 0.868, Arkadaşça Așk 0.811, Mantıklı Așk 0.803, Sahiplenici Așk 0.758 ve Özgeci Așk 0.771 olarak; RIC ölçeğinin alt boyutlarından Bireycilik 0.819, İlişkisellik 0,833, Toplulukçuluk 0.824 olarak saptanmıştır. Veri setinin iç güvenilirlik Cronbach Alfa katsayıları yüksek derecede güvenirlik vermektedir.

Örneklemi oluşturan katılımcıların Benlik Yapısı ile Romantik İlişki Biçimleri arasındaki ilişkinin tespiti için Pearson Korelasyon Analizi, cinsiyete göre benlik yapısı ile romantik ilişki biçimleri arasında anlamlı farklılık olup olmadığının tespiti için bağımsız 
örneklem t testi analizleri yapılmıștır. Araștırmadan elde edilen verilerin istatistiksel çözümlemeleri IBM SPSS 22.0 programı kullanılarak yapılmış ve araştırmada anlamlılık düzeyi [ $\mathrm{p} \leq .05]$ olarak kabul edilmiștir.

\section{Sonuçlar}

Tablo 1 Romantik İlişki Biçimleri ve Benlik Yapıları Arasındaki İlişkinin Tespiti İçin Yapilan Pearson Korelasyon Analizi

\begin{tabular}{|c|c|c|c|c|c|c|c|c|c|c|}
\hline & & Bireycilik & $\begin{array}{l}\text { İlişkisel- } \\
\text { lik }\end{array}$ & $\begin{array}{l}\text { Topluluk- } \\
\text { çuluk }\end{array}$ & $\begin{array}{c}\text { Tutkulu } \\
\text { Așk }\end{array}$ & $\begin{array}{c}\text { Oyun } \\
\text { Gibi } \\
\text { Aşk }\end{array}$ & $\begin{array}{c}\text { Arkadaşça } \\
\text { Aşk }\end{array}$ & $\begin{array}{c}\text { Mantıklı } \\
\text { Așk }\end{array}$ & $\begin{array}{c}\text { Sahiplenici } \\
\text { Așk }\end{array}$ & $\begin{array}{c}\text { Özgeci } \\
\text { aşk }\end{array}$ \\
\hline \multirow{3}{*}{ Bireycilik } & $\mathbf{r}$ & 1 & $699^{* *}$ &, $623^{* *}$ & $102^{*}$ & 0,018 & $102^{*}$ & $195^{* *}$ & 0,047 & $-0,041$ \\
\hline & $\mathbf{p}$ & & 0,000 & 0,000 & 0,041 & 0,721 & 0,041 & 0,000 & 0,349 & 0,409 \\
\hline & $\mathbf{n}$ & 400 & 400 & 400 & 400 & 400 & 400 & 400 & 400 & 400 \\
\hline \multirow{3}{*}{ İlişkisellik } & $\mathbf{r}$ & $699^{* *}$ & 1 &, $800^{* *}$ & $148^{* *}$ & $-0,015$ & 0,081 &, $163^{* *}$ &, $219^{* *}$ &, $218^{* *}$ \\
\hline & $\mathbf{p}$ & 0,000 & & 0,000 & 0,003 & 0,759 & 0,108 & 0,001 & 0,000 & 0,000 \\
\hline & $\mathbf{n}$ & 400 & 400 & 400 & 400 & 400 & 400 & 400 & 400 & 400 \\
\hline \multirow{3}{*}{ Toplulukçuluk } & $\mathbf{r}$ & $623^{* *}$ & $800^{* *}$ & 1 & 0,090 & 0,033 & $119^{*}$ &, $224^{* *}$ &, $165^{* *}$ & $148^{* *}$ \\
\hline & $\mathbf{p}$ & 0,000 & 0,000 & & 0,072 & 0,513 & 0,017 & 0,000 & 0,001 & 0,003 \\
\hline & $\mathbf{n}$ & 400 & 400 & 400 & 400 & 400 & 400 & 400 & 400 & 400 \\
\hline \multirow{3}{*}{ Tutkulu Aşk } & $\mathbf{r}$ &, $102^{*}$ & $148^{* *}$ & 0,090 & 1 & 0,061 &, $366^{* *}$ & $145^{* *}$ & $193^{* *}$ &, $407^{* *}$ \\
\hline & $\mathbf{p}$ & 0,041 & 0,003 & 0,072 & & 0,222 & 0,000 & 0,004 & 0,000 & 0,000 \\
\hline & $\mathbf{n}$ & 400 & 400 & 400 & 400 & 400 & 400 & 400 & 400 & 400 \\
\hline \multirow{3}{*}{ Oyun Gibi Aşk } & $\mathbf{r}$ & 0,018 & $-0,015$ & 0,033 & 0,061 & 1 & 0,019 & $198^{* *}$ & $140^{* *}$ & $134^{* *}$ \\
\hline & $\mathbf{p}$ & 0,721 & 0,759 & 0,513 & 0,222 & & 0,698 & 0,000 & 0,005 & 0,007 \\
\hline & $\mathbf{n}$ & 400 & 400 & 400 & 400 & 400 & 400 & 400 & 400 & 400 \\
\hline \multirow{3}{*}{ Arkadaşça Aşk } & $\mathbf{r}$ & $102^{*}$ & 0,081 & $119^{*}$ &, $366^{* *}$ & 0,019 & 1 &, $191^{* *}$ & $-0,013$ & $149^{* *}$ \\
\hline & $\mathbf{p}$ & 0,041 & 0,108 & 0,017 & 0,000 & 0,698 & & 0,000 & 0,793 & 0,003 \\
\hline & $\mathbf{n}$ & 400 & 400 & 400 & 400 & 400 & 400 & 400 & 400 & 400 \\
\hline \multirow{3}{*}{ Mantıklı Așk } & $\mathbf{r}$ &, $195^{* *}$ & $163^{* *}$ &, $224^{* *}$ &, $145^{* *}$ & $198^{* *}$ & $191^{* *}$ & 1 & $199^{* *}$ &, $123^{*}$ \\
\hline & $\mathbf{p}$ & 0,000 & 0,001 & 0,000 & 0,004 & 0,000 & 0,000 & & 0,000 & 0,014 \\
\hline & $\mathbf{n}$ & 400 & 400 & 400 & 400 & 400 & 400 & 400 & 400 & 400 \\
\hline \multirow{3}{*}{$\begin{array}{l}\text { Sahiplenici } \\
\text { Așk }\end{array}$} & $\mathbf{r}$ & 0,047 &, $219^{* *}$ & $165^{* *}$ &, $193^{* *}$ & $140^{* *}$ & $-0,013$ & $199^{* *}$ & 1 &, $463^{* *}$ \\
\hline & $\mathbf{p}$ & 0,349 & 0,000 & 0,001 & 0,000 & 0,005 & 0,793 & 0,000 & & 0,000 \\
\hline & $\mathbf{n}$ & 400 & 400 & 400 & 400 & 400 & 400 & 400 & 400 & 400 \\
\hline \multirow{3}{*}{ Özgeci aşk } & $\mathbf{r}$ & $-0,041$ &, $218^{* *}$ & $148^{* *}$ &, $407^{* *}$ & $134^{* *}$ & $149^{* *}$ &, $123^{*}$ &, $463^{* *}$ & 1 \\
\hline & $\mathbf{p}$ & 0,409 & 0,000 & 0,003 & 0,000 & 0,007 & 0,003 & 0,014 & 0,000 & \\
\hline & $\mathbf{n}$ & 400 & 400 & 400 & 400 & 400 & 400 & 400 & 400 & 400 \\
\hline
\end{tabular}


Tablo 1 analiz edildiğinde Bireycilik Benlik Yapısı ile Tutkulu Așk $(r=0,102, p$ $=0,041)$, Arkadaşça Așk, ( $r=0,102, p=0,041)$ ve Mantıklı Așk ( $r=0,195, p=0,000$ ) biçimi arasında pozitif yönlü anlamlı ilişki olduğu tespit edilmiştir. Bireycilik benlik yapısı arttıkça tutkulu aşk, arkadaşça aşk ve mantıklı aşk yașama biçimleri artmaktadır.

İlişkisellik Benlik Yapısı ile Tutkulu Așk ( $r=0,148, p=0,003$ ), Mantıklı Așk ( $r$ =0,163, $p=0,0001)$, Sahiplenici Așk ( $r=0,219, p=0,000)$ ve Özgeci aşk ( $r=0,218$, $p=0,000$ ) biçimi arasında pozitif yönlü anlamlı ilişki olduğu tespit edilmiştir. İlişkisellik benlik yapısı arttıkça tutkulu aşk, mantıklı aşk, sahiplenici ve özgeci aşk yaşama biçimleri artmaktadır.

Toplulukçuluk Benlik Yapısı ile Arkadaşça așk ( $r=0,119, p=0,017)$ Mantıklı Așk ( $r=0,224, p=0,000)$, Sahiplenici Așk ( $r=0,165, p=0,001)$ ve Özgeci aşk ( $r$ $=0,148, p=0,003$ ) biçimi arasında pozitif yönlü anlamlı ilişki olduğu tespit edilmiştir. Toplulukçuluk benlik yapısı arttıkça arkadașça aşk, mantıklı aşk, sahiplenici ve özgeci aşk yaşama biçimleri artmaktadır.

Tablo 2 Cinsiyete Göre Romantik İlişki Biçimleri Arasında Anlamlı Farklılık Olup Olmadığının Tespiti Amaçlı Yapılan Bağımsız Örneklem T Testi

\begin{tabular}{|c|c|c|c|c|c|c|c|}
\hline Cinsiyet & & $f$ & $\bar{X}$ & $s . s$. & $t$ & $s d$ & $p$ \\
\hline \multirow{2}{*}{ Tutkulu Aşk } & Kadın & 200 & 3,45 & 0,80 & $-1,291$ & 398 & 0,198 \\
\hline & Erkek & 200 & 3,55 & 0,75 & & & \\
\hline \multirow{2}{*}{$\begin{array}{l}\text { Oyun Gibi } \\
\text { Aşk }\end{array}$} & Kadın & 200 & 2,49 & 0,56 & $-4,995$ & 379,894 & 0,000 \\
\hline & Erkek & 200 & 2,81 & 0,70 & & & \\
\hline \multirow{2}{*}{$\begin{array}{l}\text { Arkadaşça } \\
\text { Aşk }\end{array}$} & Kadın & 200 & 2,98 & 0,99 & 0,624 & 398 & 0,533 \\
\hline & Erkek & 200 & 2,91 & 1,05 & & & \\
\hline \multirow{2}{*}{$\begin{array}{l}\text { Mantıklı } \\
\text { Aşşk }\end{array}$} & Kadın & 200 & 3,30 & 0,75 & 2,877 & 398 & 0,004 \\
\hline & Erkek & 200 & 3,07 & 0,86 & & & \\
\hline \multirow{2}{*}{$\begin{array}{l}\text { Sahiplenici } \\
\text { Așk }\end{array}$} & Kadın & 200 & 3,37 & 0,74 & 1,043 & 398 & 0,298 \\
\hline & Erkek & 200 & 3,29 & 0,77 & & & \\
\hline \multirow{2}{*}{ Özgeci aşk } & Kadın & 200 & 2,94 & 0,85 & $-6,367$ & 398 & 0,000 \\
\hline & Erkek & 200 & 3,49 & 0,88 & & & \\
\hline
\end{tabular}

Tablo 2'de görüldüğü üzere cinsiyete göre aşkı yaşama biçimlerinde anlamlı farklılık olup olmadığının tespit edilmesi için bağımsız örneklem $t$ testi yapılmıştır. Yapılan analiz sonucunda Oyun Gibi Aşk ( $p=0,0,000)$, Mantıklı Aşk $(p=0,004)$ ve Özgeci aşk ( $p=0,0,000$ ) yaşama biçimleri düzeylerinde cinsiyete göre anlamlı farklılık olduğu tespit edilmiştir. Erkekler oyun gibi aşk biçimini ve özgeci aşk biçimini kadınlara 
göre daha yüksek düzeyde yaşarken kadınlarda mantıklı aşk biçimini kadınlara göre daha yüksek düzeyde yaşamaktadırlar.

Tutkulu Aşk ( $p=0,198)$, Arkadaşça Așk ( $p=0,0,533)$ ve Sahiplenici Aşk ( $p$ $=0,0,298$ ) yaşama biçimleri düzeylerinde cinsiyete göre anlamlı farklılık olmadığı tespit edilmiştir. Kadın ve erkeklerin bu aşk biçimlerini yaşama düzeyleri bir birine benzerdir.

Tablo 3. Cinsiyete Göre Benlik Yapısı Düzeylerinde Anlamlı Farklılık Olup Olmadığının Tespiti Amaçlı Yapılan Bağımsız Örneklem T Testi

\begin{tabular}{|c|c|c|c|c|c|c|c|}
\hline Cinsiyet & & $f$ & $\bar{X}$ & $s . s$. & $t$ & $s d$ & \\
\hline \multirow{2}{*}{ Bireycilik } & Kadın & 200 & 53,26 & 7,24 & 2,577 & 383,252 & 0,010 \\
\hline & Erkek & 200 & 51,18 & 8,83 & & \multirow{3}{*}{398} & \multirow{3}{*}{0,177} \\
\hline \multirow{2}{*}{ İlişkisellik } & Kadın & 200 & 51,97 & 7,84 & \multirow[t]{2}{*}{1,353} & & \\
\hline & Erkek & 200 & 50,81 & 9,25 & & & \\
\hline \multirow{2}{*}{ Toplulukçuluk } & Kadın & 200 & 48,82 & 8,37 & \multirow[t]{2}{*}{0,930} & \multirow[t]{2}{*}{398} & \multirow[t]{2}{*}{0,353} \\
\hline & Erkek & 200 & 47,96 & 10,14 & & & \\
\hline
\end{tabular}

Tablo3'te cinsiyete göre benlik yapılarında anlamlı farklılık olup olmadığını test etmek için yapılan bağımsız örneklem t testi sonuçları yer almaktadır. Analiz sonuçlarına göre Bireycilik Benlik Yapısı düzeyinde anlamlı farklılık olduğu tespit edilmiştir ( $p$ $=0,010)$. Buna göre kadınların erkeklere göre daha yüksek düzeyde bir bireycilik benlik yapısına sahip oldukları tespit edilmiştir. İlişkisellik ( $p=0,177)$ ve toplulukçuluk ( $p$ $=0,353$ ) benlik yapısı düzeylerinde ise anlamlı farklılık saptanmamıștır.

\section{Tartışma}

Çalışmamızda bireycilik benlik yapısıyla; tutkulu aşk, arkadaşça aşk ve mantıklı aşk arasında anlamlı ve pozitif bir ilișki bulunmuştur. Bireyci benlik yapısı; kişinin özerk ve gruptan bağımsızlı̆̆ının ön planda olduğu bir yapıdır. Tutkulu aşkta ön planda olan fiziksel çekiciliktir, dolayısıyla bireyci kişi önceliği kendi ihtiyaçları olacak ve bunu tamamlayacağı çekici bulduğu kişiyle çevreden bağımsız bir ilişki içinde olmayı yeğleyeceği düşünülebilir. Bu bulgu, literatürle uyumludur (Ercan, 2013a). Bireyci kişiler genelde grup içinde iken kendi ihtiyaçlarını önemsediklerinden grup içi arkadaşlığın aşka dönüşmesini uygun bulabilirler. Bu durumda etkinliklere ve aynı alanlara ilginin yoğun olduğu arkadaşça aşkta; iki kişinin grubu aşan ve aslında bir anlamda gruba rağmen özerklik oluşturan arkadașça așka yönelmeleri uygun olabileceği düşünülebilir. Bu bulgu, literatürle uyumludur.

Araştırmamızda bireycilik skorları ile, mantıklı aşk skorları arasında pozitif yönlü anlamlı bir ilişki bulunmuştur. Bu bulgumuz literatürle uyumlu gözükmemektedir. Bunu Ercan'ın(2013) çalışmasında grubun eğitim yönünden homojene yakın olmasına rağmen; bizim çalıştığımız grubun üniversite öğrencilerinden oluşmasıyla ilişkili olduğu, bireyci grubun aşkta seçim yaparken ailenin bir anlamda mecburi talebi olan benzer statü, 
anlaşma durumu ve gelecekte uyumu dikkate alarak mantıklı aşk tutumunu ön plana alması şeklinde yorumlanmıştır.

Araștırmamızda; bireycilik skorları ile özgeci aşk skorları arasında bir ilişsi bulunamamıştır. Literatürde bireycilik benlik yapısıyla özgeci aşk arasında negatif yönlü bir ilişki bulunmuştur. Özgeci aşk kişinin diğeri için fedakârlığını öncelerken, bireycilik benlik yapısıyla ilişkili olmaması doğaldır. Ancak bulgularımızın homojen bir üniversite öğrencisi grubuna ait olması ve diğerinin heterojen bir grup olmasıyla farklılık göstermiş olabilir (Ercan, 2013a).

Araștırmamızda İlişkisellik benlik yapısı arttıkça; mantıklı aşk, tutkulu aşk, sahiplenici ve özgeci aşk yaşama biçimleri artmaktadır. Bu durum sahiplenici aşk stili dışında literatürle uyumludur. (Ercan, 2013). Kișinin yakın çevresindeki bireylerle ilişkisini ve onlar gibi olma durumunu içeren ilișkisellik benlik yapısında; mantıklı aşkı, yani, kişinin olumlu ve devamlılık sağlanabilecek ve geleceğe uygun, toplumdaki gibi bir aşkı tercih etmesi uygun olarak değerlendirilebilir. İlişkiselliğin önemli parçası olan özdeşim ve çevresi gibi olma haliyle; fiziksel çekiciliğin ön planda olduğu tutkulu aşkın, onaylanma ihtiyacıyla ilișkisi olabilir. Yakın çevresindeki ilișki ve onlar gibi olma halinin sahiplenici aşkın karakteristiği olan; gelgitlerin olması durumuna rağmen, ilișkiden yani bir anlamda ilişkisellikten çlkamama hali ile ilişkilendirilebilir. İlişkisellik benlik yapısının; özgeci aşk biçimiyle ilişkisinin, çevresi için çevresi gibi olma haliyle ilişkisi olabilir. Ancak çalışmamızda sahiplenici aşk ile ilişkisellik boyutu arasında pozitif yönde anlamlı bir ilişki bulunmuştur. Bulgumuz literatürden farklıdır. Ne onla ne onsuz olma hali olan sahiplenici aşktaki sevgilinin yörüngesinden çlkamama hali, ilișkisellik benlik yapısının, çevresindekilerden kopamama durumu ile ilişkili olarak değerlendirilebilir.

Araştırmamızda toplulukçuluk benlik yapısı arttıkça, arkadaşça aşk, mantıklı aşk, sahiplenici ve özgeci aşk yaşama biçimleri artmaktadır. Toplulukçuluk benlik yapısının temelini insanların benzerliği ve aynılığı üzerinden değerlendirdiğimizde, arkadaşça aşkta kişi uzun süren arkadaşlı̆̆ın aynılığı teyit etmesiyle ilişkilendirilebilir. Toplulukçuluk benlik yapısının sahiplenici aşkla ilişkisi sahiplenici aşktaki bir türlü gidememe, bırakamama, birine ait olma haliyle ilişkilendirilebilir. Toplulukçuluk benlik yapısı ile mantıklı aşkın iliş̧kisi, kişinin olumlu ve devamlılık sağlanabilecek ve geleceğe yönelik parçasının, toplumun istekleriyle örtüşen aşk modeliyle uyuşması olarak değerlendirilebilir. Toplulukçuluk benlik yapısının; özgeci aşk biçimiyle ilişkisinin, çevresi için çevresi gibi olma haliyle ilişkisi olabilir. Literatürden farklı olarak çalışmamızda toplumsalcılık benlik yapısı ile tutkulu aşk yapısı arasında bir ilişki bulunmamıştır. Bu durumu toplulukçuluk benlik yapısını, birey ve topluluk arasında simgesel bir bağ olması olarak tanımladığımızda, cinsel çekim dışında derinliği olmayan tutkulu aşkın, bireyden topluma bir simgesel değer olușturması arasında bir ilginin olmaması doğal karşılanabilir.

Çalışmamızda; erkeklerde oyun gibi aşk ve özgeci aşk, kadınlara göre anlamlı düzeyde yüksek bulunurken, kadınlarda mantıklı aşk erkeklere göre anlamlı düzeyde yüksek bulunmuştur. Buss' a göre (Buss 1988, Buss 1989) aşkın temel amacı; türün devamını sağlamak olduğu ve bu amaç için kaynak sergileme, bağlılık, koruma, evlilik, cinsel yakınlık, kaynak paylaşımı, üreme ve ana-babalık yatırımları görevlerini de yapmak gereklidir. Tam da bu nedenle kadın ve erkeğin aşk biçimlerinde farklılıklar vardır. Araştırmaya göre (Rokach \& Bacanlı, 2001) aşk biçiminde beklenen kültürel farklılıklarla birlikte evrensel ortak davranış kalıpları da mevcuttur. Oyun gibi aşkın özelliği; yakınlığın az olduğu, hatta birçok partnerle aynı anda ilişkinin kurulduğu ve stratejilerin olduğu aşk tipidir. Oyun gibi aşkın erkeklerde yüksek görülmesini evrimsel açıdan soyu sürdürme avantajı sağlamasıyla açılanabilir. Bununla birlikte Türkiye kültüründe erkeğin rolü ve davranışlarının genelde olumlu algılanması da bu tutumu destekliyor olabilir (Hill, 2003). 
Erkeklerde özgeci aşk, kadınlara göre daha yüksektir. Özgeci aşkın özellikleri cömert olmak, özverili olmak ve adanmışlıktır. Evrimsel çerçeveden bakıldığında koruyuculuk ve kollayıcılık neslin devamında erkeğin fiziksel gücüyle özdeșleșmesi olabilir. Kültürel olarak ise erkelerden beklenen, hep daha fazla sorumluluk alması yönündedir. Bu durum özgeci aşk tutumunun yüksekliğini açlklayabilir (Büyükșahin, 2006; Büyükşahin \& Hovardaoğlu, 2004; Ercan, 2013b; 2016; Fehr, Harasymchuk \& Sprecher, 2014; Hendrick \& Hendrick, 1998; 2002; Neto, 1994; Neto vd., 2000; Regan, 2016; Smith \& Klases, 2016).

Araştırmamızda bireycilik benlik yapısı ile kadın cinsiyet arasında ilişki saptanmıștır. Literatürde de çalışmamızı destekleyen kanıtlar vardır. Kadınlarda bireycilik benlik yapısı daha yüksek bulunmuștur (Ercan 2011, Karakitapoğlu-Aygün, 2004) Ancak bununla birlikte literatürde ilișkisellik benlik boyutu kadınlarla ilișkili bulunurken; çalıșmamızda erkeklere göre daha fazla gözükmesine rağmen anlamlı fark bulunamamıştır. Bunu örneklem grubunun sayısı ile ilişkilendirebiliriz (Ercan 2011, Karakitapoğlu-Aygün, 2004 ).

\section{KAYNAKÇA}

AÇIKEL, M. (2013). Üniversite öğrencilerinin aşk biçimleri ve kişilik özellikleri arasındaki ilişskinin incelenmesi (Yayımlanmamış Yüksek Lisans Tezi). Hacettepe Üniversitesi Sosyal Bilimler Enstitüsü Eğitim Bilimleri Anabilim Dalı Psikolojik Danışma ve Rehberlik Bilim Dall, Ankara.

ATAK, H., TAŞTAN, N. (2012). Romantik ilişkiler ve aşk. Psikiyatride Güncel Yaklaşımlar, 4, 520-546.

AVINASH, P.R., KALRA, G. SUBRAMANYAM, A. SHAH, H., KAMATH, R. (2015).

Love styles of young adults in a metropolitan city of India. Open Journal of Psychiatry \& Allied Scienes, 6 (2), 83-88.

BANAJI, M.R., PRENTICE, D.A. (1994). The self in social context. Annu. Rev. Psychol. 4, 297-332.

BRESNAHAN, M.H., CHIU, H.C., LEVINE, T.R. (2004). Self-Construal as a Predictor of Communal and Exchange Orientation in Taiwan and the USA. Asian Journal of Social Psychology, 7, 187-203.

BRESNAHAN, M.J., LEVINE, T.R., SHEARMAN, S.M., LEE, S.Y., PARK, C., KIYOMIYA, T. (2005). A Multimethod Multitreit Validity Assessment of Self-Construal in Japan, Korea, and The United States. Human Communication Research, 31 (1), 33-59.

BUSS, D.M. (1988). The evolution of human intrasexual competition: Tactics of mate attraction. Journal of Personality and Social Psychology, 54 (4), 616-628.

BUSS, D.M. (1989). Sex differences in human mate preferences: Evolutionary hypotheses tested in 37 cultures. Behavioral and Brain, 12 (1), 1-49.

BÜYÜKŞAHIN, A., HOVARDAOĞLU, S. (2004). Çiftlerin aşka ilişkin tutumlarının Lee'nin çok boyutlu aşk biçimleri kapsamında incelenmesi. Türk Psikoloji Dergisi, 19, 5972.

CARPENTER, S., KARAKITAPOĞLU-AYGÜN, Z. (2005). Importance and Descriptiveness of Self-Aspects: A Cross-Cultural Comparison. Cross-Cultural Research, 39 (3), 293-321.

ÇUHADAROĞLU, A., AKFIRAT, O . (2017). Examining The Relationship Between Self-Construal and Gender Perceptions of University Students. Gaziantep University Journal of Social Sciences, 16 (4), 1031-1046. DOI: 10.21547/jss.304500 
DAVIES, M.F. (2001) Socially desirable responding and impression managamet in the endorsement of love styles. The Journal of Psychology,135 (5), 562-570.

DION, K.K., DION, K.L. (1988). Romantic love: Individual and cultural perspectives. In. Sternberg R.J. \& Barnes, M.L. (Eds.), The Psychology of Love. (264-292. ). New Haven: Yale University Press.

DION, K.K., DION, K.L. (1993). Gender and ethnocultural comparisons in style of love. Psychology of Woman, 17, 463-473.

DURMAZ, H., ERCAN, H., (2019) Beliren Yetişkinlikte Așk Stillerinin Demografik Değiş̧kenler, Ana Babaya Bağlanma ve Kişilik Özellikleri Açısından İncelenmesi. Başkent University Journal of Education, 6(1), 98-110.

ERCAN, H. (2011). İlişkisel-Bireyci Toplulukçu Benlik Ölçeği'nin Psikometrik Özellikleri ve Uyarlama Çalışması. KMÜ Sosyal ve Ekonomik Araştırmalar Dergisi, 13 (21), $37-45$

ERCAN, H. (2013a). Analysis of Young Adults' Love Styles According to Their SelfConstruals and Demographic Variables. Turkish Studies, 8 (12), 479-493.

ERCAN, H. (2013b). Bilimsel bir araştırma alanı olarak aşk. (İç. F. Çok \& C. Karadeniz (Ed.), Prof. Dr. Bekir Onur’a Armağan s.245-278). Ankara: Anı Yayıncılık.

ERCAN, H. (2016). Üniversite öğrencilerinin aşk stillerinin demografik değișkenler ve ana babaya bağlanma ile ilișkisi. Adnan Menderes Üniversitesi Eğitim Fakültesi Ĕ̆itim Bilimleri Dergisi, 7(1), 25-37.

ERTEN, Y. (2002) Freud'dan Günümüze Kuram ve Uygulamalar. Kendilik Psikolojisi: Heinz Kohut ve Sonrası. 3 P Dergisi, 10 (3) Ek sayı.

FEHR, B., HARASYMCHUK, C., SPRECHER, S. (2014). Compassionate love in romantic relationships: A review and some new findings. Journal of Social and Personal Relationships, 31(5), 575-600.

HARDIE, E.A., KASHIMA, E.S., PRIDMORE, P. (2005). The Influence of Relational, Individual and Collective Self-Aspects on Stress, Uplifts and Health. Self and Identity, 4, 124.

HENDRICK, C., HENDRICK, S. (1986). A theory and method of love. Journal of Personality and Social Psychology, 50, 392-402.

HENDRICK, S., HENDRICK, C. (1995). Gender differences and similarities in sex and love. Personal Relationships, 2, 55-65.

HENDRICK, C., HENDRICK, S., DICKE, A. (1998). The Love Attitudes Scale: Short Form. Journal of Social and Personal Relationships, 15(2), 147-159.

HENDRICK, C., HENDRICK, S. (2002). Linking romantic love with sex:

Development of the perceptions of love and sex scale. Journal of Social and Personal Relationships, 19(3), 361-378.

HOFSTEDE, G., (1980). Culture's consequences: International differences in workrelated values, Beverly Hills, CA: Sage.

HILL B.,(2003). Bizans Imparatorluk kadınları (1025-1204) Iktidar, Himaye ve İdeoloji. (Çev. E. Gökteke Tut), s.12., İstanbul: Tarih Vakfı Yurt Yay.

İMAMOĞLU, E.O. (1998). Individualism and Collectivism in A Model and Scale of Balanced Differentiation and Integration. Journal of Psychology, 132 (1), 1-8. .

İMAMOĞLU, E.O. (2003). Individuation and Relatedness: Not: Opposing but

Distinct and Complementary. Genetic, Social, and General Psychology Monographs, 129 (4), 367-402.

KAĞITÇIBAŞI, Ç. (1996). Özerk-İlişkisel Benlik: Yeni Bir Sentez. Türk Psikoloji Dergisi, 11 (37), 36-4

KAĞITÇIBAŞI, Ç. (2001). Development of self and competence in cultural context. Second Edition. NIAS: Wassenaar. 
KAĞITÇIBAȘI, Ç. (2002). Psychology and Human Competence Development. Applied Psychology: An International Review, 51 (1), 5-22.

KAĞITÇIBAŞI, Ç. (2005). Autonomy and Relatedness in Cultural Context. Journal of Cross-Cultural Psychology, 36 (4), 403-422

KAĞITÇIBAȘI, Ç. (2010). Günümüzde insan ve insanlar: Sosyal psikolojiye giriş. (12. Basım). İstanbul: Evrim Yayınevi.

KAĞITÇIBAŞI, Ç. (2012). Benlik, aile ve insan gelişimi: Kültürel psikoloji. (3. Baskı). İstanbul: Koç Üniversitesi Yayınları.

KARAKITAPOĞLU-AYGÜN, Z. (2004).Self, Identity, Emotional Well-Being Among Turkish University Students. The Journal of Psychology, 138 (5), 457-478.

KASHIMA, E., HARDIE, E.A. (2000). The Development and Validation of the Relational, Individual and Collective Self Aspects (RIC) Scale. Asian Journal of Social Psychology, 3, 19-48.

KASHIMA, Y., KASHIMA, E., CHIU, C., FARSIDES, T., GELFAND, M. HONG, Y., KIM, U., STRACK, F., WERTH, L., YUKI, M., YZERBYT, V. (2005). Culture, Essentialism, and Agency; Are Individuals Universally Believed to be more Real Entities than Groups. Europen Journal of Social Psychology, 35, 147-169.

KOHUT, H. (1971). Kendiliğin çözümlenmesi (Çev. C. Atbaşoğlu, B. Büyükkal, C. İscan). s:88-100. İstanbul: Metis Yayınları.

KOHUT, H. (1977). Kendiliğin yeniden yapılanması. (Çev. O. Cebeci). s.155-157. İstanbul: Metis Yayınları. Madison.

KOHUT, H. (1987). The analysis of the self. International Universities Press: Madison.

KOHUT, H. (1988). The restoration of the self. International Universities Press.

LALONDE, N.R., HYNIE, M., PANNU, M., TATLA, S. (2004). The Role of Culture in Interpersonal Relationships. Journal of Cross-Cultural Psychology, 35 (5), 503-524.

LE, T.N. (2005). Narcissism and immature love as mediators of vertical individualism and ludic love style. Journal of Social and Personal Relationships, 22 (4), 543-560.

LEE, J.A. (1974). The Styles of Loving. Psychology Today, 8, 44-51.

LEE, J.A. (1988). Love styles. (Ed: R. J. Sternberg and M. L. Barnes), The Psychology of Love. New Hawen: Yale University Pres.

MADSON, L., TRAFIMOW, D. (2001). Gender Comparison in the Private, Collective and Allocentric Selves. The Journal of Social Psychology, 141 (4), 551-559.

MARKUS, H.R., KITAYAMA, S. (1991). Culture and The Self: Implications for

Cognition Emotion and Motivation. Psychological Review, 98, 224-253.

NETO, F. (1994). Love styles among Portuguese students. The Journal of Psychology, 128(5), 613-616.

NETO, F., MULLET, E., DESCHAMPS, J. C., BARROS, J., BENVINDO, R., CAMINO, L., FALCONI, A., KAGIBANGA, V. MACHADA, M. (2000). Cross-cultural variations in attitudes toward love. Journal of Cross-Cultural Psychology, 31(5), 626-635.

PHILBRICK, J.L., STONES, C.R. (1988). Love-attitudes of white South African adolescents. Psychological Reports, 62, 17-18.

REGAN, P.C. (2016). Loving unconditionally: Demographic correlates of the agapic love style. Interpersona: An International Journal on Personal Relationships, 10(1), 28-36.

ROSENMAN, M.F. (1978). Liking loving and styles of loving. Psychological Reports, 42, 1243-1246.

ROKACH, A., BACANLİ, H. (2001). Perceived causes of loneliness: a cross-cultural comparison. Social Behavior and Personality, 29 (2), 169-82. 
ROTENBERG, K.J, SHEWCHUK, V.A, KIMBERLEY, T. (2001) Loneliness sex romantic jealousy and powerlessness. J Soc Pers Relat. 18, 7-19.

RUBIN, Z. (1970). Measurement of romantic love. Journal of Personality and Social Psycholog, 16(2), 265-273.

RUBIN, Z., PEPLAU, L.A., HILL, C.T. (1981). Loving and leaving: Sex differences in romantic attachments. Sex Roles, 7(8), 821-835.

RUBIN. Z. (1988). Preface. (Eds. In. R.J. Sternberg \& M.L. Barnes. The Psychology of Love).New Haven: Yale University Press.

SHARMA, S., KHANDELWAL, K. (2014). Effect of gender and life-stage on love styles in the Indian context. Psychological Studies, 59(1), 22-29.

SMITH, R., KLASES, A. (2016). Predictors of love attitudes: The contribution of cultural orientation, gender attachment style, relationship length and age in participants from the UK and Hong Kong. An International Journal on Personal Relationships, 10(1), 90-108.

SINGELIS, T.M. (1994). The measurement of independent and interdependent self construals. Personality and Social Psychology Bulletin, 20,580-591.

SINGELIS, T.M., SHARKEY, W.F. (1995). Culture, self construal and embarrassability. Journal of Cross-Cultural Psychology, 26, 622-644.

STERNBERG, R.J., GRAJEK, S. (1984). The nature of love. Journal of Personality and Social Psychology, 47, 312-329.

STERNBERG, R.J. (1999) Cupid's arrow: The course of love through time. UK: Cambridge University Press,

TUFAN. A.S., YALUĞ, İ. (2010). Așk fenomeni ve sevgi ilişkilerinin nörobiyolojisi. Psikiyatride Güncel Yaklaşımlar, 2(4). 444-445.

TRIANDIS, H.C. (2001). Individualism-Collectivism and Personality. Journal of Personality, 69 (6), 907-924.

ULEMAN, J.S., RHEE, E., BARDOLIWALLA, N., SEMIN, G. AND TOYOMA, M. (2000).

The Relational Self: Closeness to Ingroups Depends on Who They are, Culture, and the Type of Closeness. Asian Journal of Social Psychology, 3, 1-17.

ÜSKÜL, A.K., HYNIE, M., LALONDE, R.N. (2004). Interdependence as a Mediator Between Culture and Interpersonal Closeness for Euro-Canadians and Turks. Journal of Cross-Cultural Psychology, 35 (2), 174-191.

YÖYEN, E. (2017) Üniversite Öğrencilerinin Benlik Saygısı ve Yalnızlık Düzeylerinin İncelenmesi. Kastamonu Eğitim Dergisi Cilt 25 (6), 2187.

\section{Summary}

Self is an abstract, important concept that will help us to understand our psychological structure. Cultural characteristics play a role in shaping different selfconstructions and through self-construality; it affects people's cognition, feelings and impulses. Another phenomenon that influences the cognition, emotions and impulses of man is the phenomenon described by the romantic relationship concept or love. Culture and individuality are important in the definition of love.

The data of this study, which examines the relationship between self structure, romantic relationships and gender, were obtained from 400 university students studying at Istanbul Gelisim University, Faculty of Economics, Administrative and Social Sciences during the fall semester of 2018-2019 academic year.

In our study, a significant positive relationship was found between individualism scores and logical love scores, and the finding was interpreted as the fact that the 
individualist group made a choice in love, taking into account the sense of love in the sense that the family has a compulsory demand in the sense of similar status, agreement status and future compliance.

Relativity in our research as the self-structure increases; logical love, passionate love, increasing forms of life are possessive and altruistic love. The relationship between individuals in their immediate surroundings and the relationship between them, such as the relationship in the structure of the self; logical love, that is, it can be considered appropriate if the person chooses a love that is positive and sustainable and suitable for the future and society. In the form of identification and environment, which is an important part of the relationship; The passionate love in which physical attractiveness is at the forefront may be related to the need for approval. The relationship in the immediate vicinity and the possessive transcendent characteristic of being like them; In spite of the fact that there are tides, it can be associated with the relationship from the relationship, in other words, from being out of relationality. Relationality of ego structure; The relationship between altruistic forms of love can be related to the environment of its surroundings. However, in our study, a significant positive correlation was found between the affection and the affection dimension. Our findings differ from the literature. The state of being unable to get out of the orbit of the lovers in the possessive love, with and without her, can be evaluated in relation to the relation status of the relationality of the self.

In our study, as the self-structure of self-organization increases, friendly love, rational love, and possessive and altruistic love life forms are increasing. When we evaluate the basis of communityism based on the similarity and similarity of human beings, it can be attributed to the long-lasting friendship affinity with friendly love. The relation of the selforganization structure with the possessive love can be related to the fact that the owner cannot go, cannot leave, and belongs to one. The relationship between the sense of community and the sense of friendship can be considered as the positive and sustainability of the person and the future-oriented part of the society, which corresponds to the love model that coincides with the wishes of the society. Communityism of the structure of the self; The relationship between altruistic forms of love can be related to the environment of its surroundings. Unlike the literature, in our study, there was no relationship between the selfstructure of socialism and passionate love structure. When we describe this situation as a symbolic connection between the individual and the community, the lack of a deep love outside sexual attraction and the lack of interest between the individual and the creation of a symbolic value for society can be regarded as natural.

Our research; love and altruistic love were found to be significantly higher in males than in females, whereas in males, sensible love was found to be significantly higher than males. It can be explained by the fact that it has the advantage of maintaining a high level of evolution in the male, such as game, in an evolutionary way. It is thought that the altruistic love is higher in males and that protectionism and self-reliance are identified with male physical strength in the continuation of generation. Lastly, the relationship between individualism and female gender was found in our study. There is also evidence supporting our work in the literature. 